\title{
Trashion: The Return of the Disposed Bahar Emgin
}

That objects lead "social lives" of their own as they move through their biographies and undergo successive shifts in their commodity status has already been acknowledged. ${ }^{1}$ Igor Kopytoff, a professor of anthropology, introduced the notion of commoditization "as a process of becoming rather than as an all-or-none state of being." 2 The idea that objects do not enjoy an unending commodity status but that their lives are marked by the ebb and flow between a commodity and non-commodity was central to Kopytoff's argument. As such, Kopytoff wrote, the biography of an object was considerably similar to that of a person: occupying different positions, leading diverse careers in the course of different periods between a beginning and an end, being defined by different regimes of value that are both economically and culturally inscribed.

In light of this argument, one could claim that the end of the life of an object corresponds to the moment in which it is disposed of. This disposal might take place in different forms and for different reasons; however, in the most literal and common sense, the life of an object ends in a trashcan in the form of waste. In this moment, the object is left valueless in all the possible meanings of the term value: It can no more serve a function, it can on no account be exchanged for anything else, and it can by no means engage in the processes of signification to connote and endow its user with specific social values.

This article is about those objects that are recreated from trash through the process of upcycling. Upcycling is a term used by architect and designer William McDonaugh and chemist Michael Braungart and refers to "the process of converting an industrial nutrient (material) into something of similar or greater value, in its second life." ${ }^{4}$ I argue that design, in this instance, acts as a tool of transformation and reintroduces into certain orders what was once deemed waste. This theory counters the argument that an object is dead once it is disposed of.

Such a conceptualization of waste as "the degree zero of value" has been contested for some time in different disciplines, ranging from economics to environmental studies, but most particularly by those studying consumerism or material culture. ${ }^{5}$ To give an example, recycling has been endowed with a wide variety of economic, environmental, and moralistic claims. Gay Hawkins 
elaborates on the changing meanings of waste disposal and the evolving attributions of recycling in her article titled "Plastic Bags: Living with Rubbish." Referring to the work of Susan Strasser, Hawkins argues that disposal was central to the logic of mass production and hence should not be assessed as only particular to consumerism in the twentieth century: "Mass production of objects and their consumption depends on widespread acceptance of, even pleasure in, exchangeability; replacing the old, the broken, the out of fashion with the new. The capacity for serial replacement is also the capacity to throw away without concern." ${ }^{6}$ What Strasser underlines in Waste and Want, and what Hawkins agrees with in her article, is the idea that "the ethos of disposability" was fostered by the "desire for possession or convenience" as early as the $1860 \mathrm{~s}$, leaving behind all concerns for the afterlife of the trash. ${ }^{7}$ According to this idea, the emergence of a consumer society in the 1950s only made the joy of disposing, which was once a privilege of the upper classes, accessible to the masses. Within the regimes of value of mass production, disposal was coded as an act directed toward renewal, restoration, and purification; thus, the process of disposing was not yet loaded with moral or ethical connotations. ${ }^{8}$

On the contrary, with respect to the issue of disposability, waste was handled merely "as a technical problem, something to be administered by the most efficient and rational technologies of removal." ${ }^{\prime 9}$ Only through the rise of environmental movements in the 1960s did the disposal of waste come to be loaded with negative meanings and viewed through a moral framework. The enormous quantities of waste accumulating in urban centers, Hawkins writes in "Plastic Bags," were not only taken as a threat to the environment, but also as a sign of an individualistic, insensitive, and hedonistic consumer society. ${ }^{10}$ Waste now became evil. If the environment is to be saved from our destructive power, then waste should be "managed," Hawkins asserts. ${ }^{11}$ Consequently, recycling gained its contemporary prominence "as virtue-added disposal ... disposal in which the self is morally purified, disposal as an act of redemption." ${ }^{12}$ Disposal in the form of recycling is now a moralistic attitude through which we pay the debt we owe to the world.

The new, growing trend of trashion can be assessed within with Rubbish," International Journal of Cultural Studies 4:1 (2001): 9. For the history of rubbish, see Susan Strasser, Waste and Want: A Social History of Trash (New York: Metropolitan Books, Henry Holt and Company, 1999).

7 Hawkins, "Plastic Bags," 9.

8 Ibid., 10.

9 lbid.

10 Ibid.

11 Ibid., 11.

12 Ibid., 14.

13 "Trashion," http://en.wikipedia.org/wiki/ Trashion (accessed January 6, 2010). 
from a desire to make the best use of limited resources." ${ }^{14}$ The most outstanding examples of trashion can widely be found among the booming fields of green or eco-friendly design or the do-it-yourself (DIY) movement. Trashion emerges first and foremost as a claim to fulfill the aforementioned moral and ethical responsibility, in the same way that recycling or waste management are promoted as a means of "assuaging our guilt about the planet, being virtuous for the neighbors and engaging in a form of disciplinary individualism that is both voluntary and coercive at the same time," according to Hawkins. ${ }^{15}$ By means of upcycling or trashion, waste can experience a rebirth and therefore a second chance of being used and reintegrated into exchange or identification processes. Thus, not only is the environment purified by upcycling, but people involved in trashion, as both designers and users, are also ennobled by virtue of their commitment to nature and humanity.

However, to consider either recycling or upcycling merely as moral issues would be misleading. On the other side of the coin is the business stemming from these practices; recyclers not only ease their conscience through recycling; they also make a profit. Recycling, as "the huge tertiary sector devoted to getting rid of things, is central to the maintenance of capitalism; it doesn't just allow economies to function by removing excess and waste-it is an economy, realizing commercial value in what's discarded," Hawkins and Muecke write in Culture and Waste. ${ }^{16}$ In the same manner, upcycling has already been turned into a business: Certain designers labeled eco-friendly are earning money through upcycling, competitions are organized around trashion, numerous websites are devoted to promoting and selling upcycled objects, and online and print resources explain how to upcycle at home. In short, there is a whole sector of upcycling now.

Only mentioning the moral and economic aspects of upcycling and arriving at a conclusion regarding the consequences of it for consumer culture would be cutting corners. There is still more complexity to the issue than appreciating upcycling for its ethical stance or blaming it for being only another means of commoditizing. What is left untouched in this account, Hawkins and Muecke point out, and what is more promising for an analysis of trashion, is the "cultural economy of waste" that "can work on different strata: symbolic, affective, historical and linguistic." ${ }^{17}$ First, as Hawkins and Muecke point out, this approach requires an emphasis on the "hierarchical, ordered, and systematic determinations of value." ${ }^{18}$ In addition, a new conception of waste, which does not handle rubbish as valueless and evil, is required. Only from this perspective can we acknowledge waste as an active agent in the regimes of value. For

14 Ibid.

15 Hawkins, "Plastic Bags," 12.

16 Hawkins and Muecke, "Introduction," x.

17 Ibid. xvi.

18 Ibid. this reason, I introduce in the following section the changing conceptions of waste that are central to my analysis of trashion. 


\section{Re-considering Waste}

Contributions to the reconsideration of the notion of waste have, to a great extent, come from the field of anthropology. Ethnographic studies on gift and potlatch, burial rites and sacrifice, as well as studies of consumption itself, influenced certain scholars and gave rise to the questioning of old notions of waste and disposal. Kevin Hetherington is one scholar who has considered the subject in light of the studies on disposal by Mary Douglas, Roland Munro, and Michael Thompson. Hetherington begins his analysis with a refusal to see the concept of disposal as "the last act that leads inexorably to a closure of a particular sequence of production-consumption events." ${ }^{19}$ Disposal for him lies at the heart of consumption and is as central as the accumulation of objects to "managing social relations and their representation around themes of movement, transformation, incompleteness, and return." ${ }^{20}$ In this respect, Hetherington writes that a spatial dimension is added to the issue of disposal, and it becomes a matter of "placing" rather than discarding:

[D]isposal is a continual practice of engaging with making and holding things in a state of absence, [with] any notion of return (beyond simple equations of return with green recycling), or [with] any notion of understanding how something can be in a state of abeyance or "at your disposal" and what the effects of that might be. ${ }^{21}$

Once the linear passage from production to consumption and lastly to disposal is broken, the role of disposal in the processes of both individual and social ordering becomes apparent. Disposal is not an end to these processes in succession, but a matter of putting things in a state of absence, invisibility, or remoteness - either metaphorically or literally-through a process of valuation, and in this manner, disposal-keeping certain things as "matter out of place"-functions to stabilize the processes of ordering, Hetherington writes..$^{22}$ However, the discussion at this level is quite structuralist, according to Hetherington, and is directed toward maintaining a definite and stable social order. The significance of disposal for consumption can only be assessed if disposal is viewed "as a recursive process." ${ }^{23}$ That is, disposal is never complete; objects can never be disposed of 100 percent, but they fluctuate between a state of absence and a state of presence. The disposed always carries with it the possibility of coming back: "Its capacity for translation remains as an absence just as much as when a presence is encountered." ${ }^{24}$

In Culture and Waste: The Creation and Destruction of Value, John Frow deals with the issue of waste by opposing the theories that handle it as "the degree zero of value" or "the opposite of value" or "whatever stands in excess of value systems grounded in use." 25 He refers to the role of waste in constructing value in this way: "On of Value, ed. Gay Hawkins and Stephen Muecke (Oxford: Rowman \& Littlefield Publishers, 2003), 25. 
the one hand it is residually a commodity ... On the other hand, the category of waste underpins any system of social distinction, as the principle of uselessness that establishes a non-utilitarian symbolic order." ${ }^{26}$ Similar to that of Hetherington, the symbolic order or the systems of value that Frow defines are far from being definite, closed, and static structures. On the contrary, value is always referred to as a "process, a movement, a cycle" being defined, contested, and redefined over and over again. ${ }^{27}$ Within such a value system, waste or rubbish retains its chance of return and is even bestowed with the chance to define a completely new regime of value, disturbing the orderings and classifications that are based on the preceding one.

For both Hetherington and Frow, waste-or the valuelesscan always reach a totally adverse state of high value, and even overvalue, and they both elucidate this possibility through references to Michael Thompson's Rubbish Theory. As Hetherington explains, Thompson in his study defines three different classes of objects: durable, transient, and rubbish. Durable objects are marked by their high status and hence they are, in a manner of speaking, dignified; transient objects cannot enjoy a life-long high status, and their value decreases gradually over time; and rubbish, as the last category, can by no means be valued: "They become blanks that can address not only the question of value in the singular instance but also value as a general category." ${ }^{28}$ The status of objects in the categories of both durable and transient is clearly defined; the codes that assign these objects to their categories are fixed; and their value is under the control of social agents who strive to maintain the existing ordering. ${ }^{29}$ However, the case for rubbish objects is different; they are free from the control exerted on the other two categories. Hetherington writes that they stand on "a blank and fluid space between the other two categories, helping to maintain their separateness while also providing a conduit for objects to move back and forth into the regions of fixed assumptions." ${ }^{30}$ Hetherington criticizes Thompson's classification for its stress merely on exchange, which he says overlooks other possible ways of valorizing an object (e.g., a sentimental valorization). Nevertheless, for both Hetherington and Frow, the value of Thompson's classification lies in the manner in which it opens up a dynamic space that allows a transition between categories and thus transformations in status, which in turn introduces fluidity to value systems. In light of Thompson's classification, it becomes possible to conceptualize rubbish as the "conduit of disposal rather than that which is placed in the conduit." ${ }^{\prime 1}$

At this point, Hetherington introduces a new metaphor and

26 Frow, "Invidious Distinction,"26.

Ibid., 35

8 Hetherington, "Secondhandedness," 164.

29 Ibid.

30 Ibid., 165.

31 Hetherington, "Secondhandedness," 164. 
outside/inside, present/absent, at least temporarily and provisionally." ${ }^{2}$ Thus, not only is the process of disposal flexible, but the conduits of disposal are themselves fluid, undermining through the process of transfer any possibility of stability in the regimes of value used.

The passage of the objects through these conduits can end either in de-commoditization, namely in prolonging the priceless state of being - not at the level of zero value this time, but at the level of such a high value that there can be no equivalent for it in any exchange system or in commoditization. Commoditization, here, would rather be referred to as re-commoditization since the object in question had once been a commodity before it moved through the conduit of disposal. Collection constitutes an example of the former, while trashion provides an example of the latter. Hetherington also refers to collection as a conduit of disposal:

Still, much collecting derives its meaning precisely from this dynamic - the making of the reputation of an object (and thereby its status and value) by making it visible, recognisable, and "respectable" (including cult or subcultural respectability with respect to kitsch). A cheap, contemporary, utilitarian object can be disposed of by one generation only to return later and be claimed as a design classic by the next. ${ }^{33}$

Valorization through the conduit of collection is not performed at the level of exchange value because the object of collection does not gain an extensive exchangeability; on the contrary, its exchangeability for anything else is substantially restricted. Through this process, the act of "singularization" can be pointed to as the creator that counteracted the object's commoditization. Singularization, as defined and elucidated by Kopytoff, is a process by which things are deprived of their commodity status through a withdrawal from the sphere of exchange. ${ }^{34}$ The struggle between singularization and commoditization begins at the very moment that the actual exchange is accomplished - when the thing is stripped of its unquestionable commodity status. ${ }^{35}$ From this moment on, the thing is vulnerable to several processes of individual or collective singularizations, which in turn deactivate it as a commodity and cause shifts in its biography.

For the waste, which has been left valueless, singularization would not come to mean decommoditization but would mean that the object is prevented from being commoditized; valorization occurs in the form of sacralization. ${ }^{36}$ In this manner, the object is given value at the level of symbolic exchange, as explicated by Jean Baudrillard in For a Critique of the Political Economy of Sign; these objects of collec-

32 Ibid.

33 Ibid., 165.

34 Kopytoff, "The Social Life of Things," 74

35 Ibid., 83.

36 Kopytoff, "The Social Life of Things," 80. 


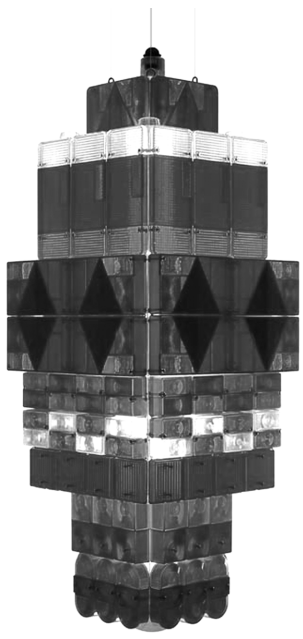

Figure 1

Tail Light by Stuart Haygarth.
37 Jean Baudrillard, For a Critique of the Political Economy of Sign (St. Louis: Telos Press Publishing, 1981), 64-5.

38 "25 Innovative Re-Purposed Home Fittings Designs," FreshBump, http://www.freshbump.com/featured/ featured/25-innovative-re-purposedhome-fittings-designs/ (accessed April 1, 2009). personally with regard to the place it occupies within social relations; it thus becomes invested emotionally rather than monetarily. ${ }^{37}$

In the following section, I concentrate on the issue of trashion as a conduit of disposal and, offering examples, elaborate on the consequences of such transformation for the issue of consumption.

\section{Design as a Conduit of Disposal}

Design has now turned into an indispensable aspect of marketing strategies, whereby products are inculcated with added value. Thus, products can be differentiated in the market, tailored to the presumed tastes and choices of socially and culturally differentiated target groups. In this respect, it is not surprising that the world of rubbish has become a treasure for design-a profession considerably involved in the generation of value through a creative process. In this treasure, we find not only objects that are disposed of, but also forgotten styles, archaic technologies, and bits and pieces that never had the chance of acquiring any value. The magic wand of design transforms these worthless, forgotten, neglected, and thrown out items into precious pieces of aesthetic and moral value. In this manner, design opens the door for the trashy to flow toward the world of the valuable and valued.

The Tail Light (see Figure 1), by Stuart Haygarth, constitutes a good example for the issue in question. The light is included on a list of "25 Innovative Re-purposed Home Fittings Designs" generated by FreshBump, a social news medium devoted to the fields of advertising, architecture, computer arts, graphic design, illustration, industrial design, interior design, and photography.

The light, which, as its name suggests, is made of vehicle tail lights, is promoted on the FreshBump website as follows: "A busted tail light can you get pulled over, but it can also give you a creative new light fixture. Artist Stuart Haygarth was inspired by lenses covering vehicle lights, seeing in them something more elevated than banal tail lights." ${ }^{38}$ Vehicle lights, which have never been considered objects in their own right, are now "elevated" to the status of a designed object, with an unexpected increase not only in their aesthetical attributes but also in their price. Thus, this trivial, insignificant, plastic thing is successfully commoditized by flowing in the opposite direction in the conduit of disposal.

Another item taken from the same list is the Cassette Cabinet (see Figure 2). In making something from what we have lost through the advances of technology, this cabinet valorizes nostalgia:

Mixtapes have long been used to commemorate love (and heartbreak), season changes, irrational obsessions with a band, and life milestones. (It's easier to turn 30 when it's to the soundtrack of Aretha Franklin.) Now that we're in 


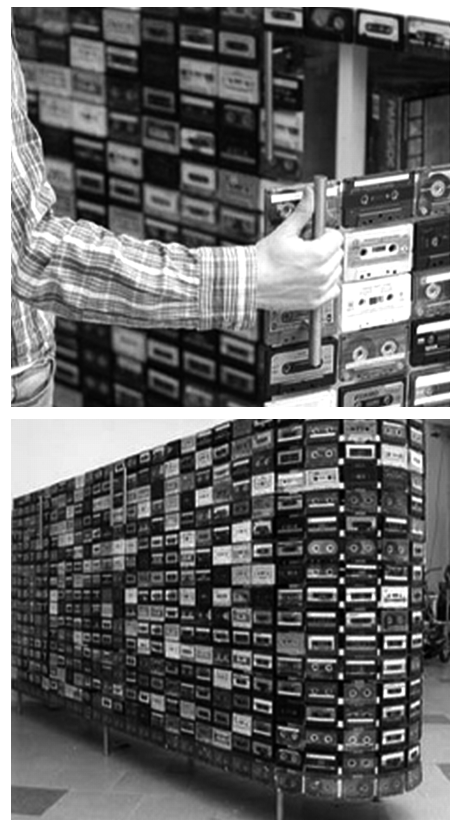

Figure 2

Cassette Cabinet by Patrick Schuur (Photo by Wouter Walmink).
39 Ibid.

40 Ibid.

41 Frank Willems official webpage, http:// www.frankwillems.net/ laccessed October 24, 2011).

42 Ibid.

43 Hetherington, "Secondhandedness," 169. the compact disc age, you're stuck with cassette tapes filled with dated music and emotions, but all's not lost. Creative Barn shows how tapes can serve a more valiant purpose than collecting dust. ${ }^{39}$

The cabinet, designed by Patrick Schuur, was made by placing 918 cassette tapes on a wooden frame structured to create a spacious storage area. It endows the once-useless mountain of garbage with a new function. In addition, this monument of archaic cassettes unearths and pays tribute to the distant memories, forgotten moments, and absent people embedded in those memories.

One last example from the list is the mattress chair, Madam Rubens, designed by Frank Willems (see Figure 3). ${ }^{40}$ In the designer's description, "Madam Rubens is a plump but sophisticated lady after an extreme makeover. She started her life as a mattress but was thrown away after years of loyal service." ${ }^{41}$ Recognizing that mattresses cannot be recycled, the designer develops this solution, guided largely by an environmentalist responsibility. The chair is a combination of a disposed mattress and the legs of an antique chair. For each chair, the mattress is folded in a different way and combined with different chair legs to assure that Madam Rubens is unique every time. The chair also is painted in a bright vivid color of choice to complement its newish look. Thus, "Madam Rubens is back in business as a fresh, hygienic, and exceptionally stylish tool." ${ }^{42}$

If these old-fashioned table legs were not combined in such an innovative manner with an already discarded mattress, they would likely be thrown away to be replaced by brand-new minimalist ones and would never be re-placed in the first place, at home. Moreover, the mattress, which has never been put on display before, steps up to the living room as an object of distinction. Any traces of outdatedness and mediocrity are erased and re-valued through a redefined function and a chic appearance. In this case the style is rescued from the past and its remnants, translated through the conduits of disposal, are transformed into a new design language.

All these translations can be considered reincarnations or rebirths, following Hetherington's adaptation of the two-phased burial practices in certain cultures that are introduced by Hertz to the realm of inanimate objects. The first place of burial for the objects can be "the bookcase, the recycle bin on a computer, the garage, the potting shed, the fridge, the wardrobe, even the bin" in which the objects are left for some time "while their uncertain value state is addressed . . . before being removed into the representational outside, where they undergo their second burial in the incinerator, the landfill, or unfortunately sometimes just fly-tipped onto the side of the road." ${ }^{\prime 3}$ The interval between the two processes is of great 


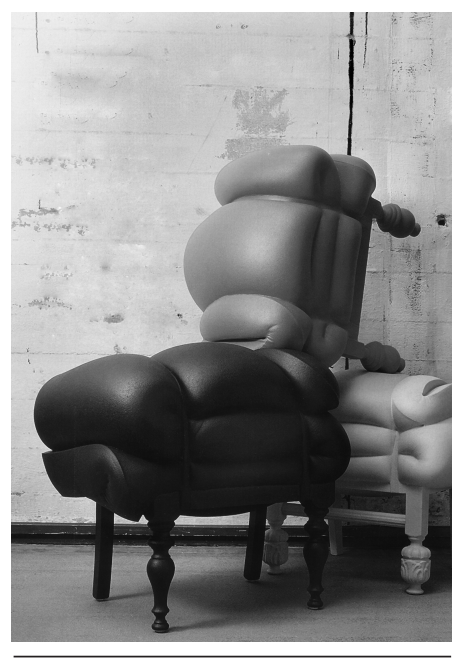

Figure 3

Madam Rubens by Frank Willems. importance for the purposes of re-valuation. Only after the second burial can we manage to totally be rid of the object; in other words, "only when all forms of value have been exhausted or translated and thereby stabilised will the object be permitted to undergo its second burial." ${ }^{44}$

But making sure that the second burial is accomplished it is not really possible. And failure in this second burial brings all these objects back, endowed with a higher status as designed objects. In their new status, the objects gain all the possible values: use value, exchange value, and sign value. Different from collection objects, these endowed objects enter into all possible spheres of exchange, or they come back as totally commoditized. They are no longer ordinary objects of everyday use but are elevated to the status of what is aesthetically tasteful, "classy stuff." In this place the power of this rebirth lies. Design, as a conduit of disposal, reintroduces rubbish as objects of distinction, invaluable and potentially priceless. People are often eager to see objects that were once considered useless and tasteless when they have been invigorated with new life. 